\title{
LOW-COST, HOLISTIC APPROACH TO ACTIVE LEARNING IN INFORMATION TECHNOLOGY
}

\author{
Shannon W. Beasley, Middle Georgia State College, shannon.beasley@maconstate.edu \\ Kevin S. Floyd, Middle Georgia State College, kevin.floyd@maconstate.edu
}

\begin{abstract}
The curriculum of a program in information technology must be current and competitive to remain relevant and valuable. The authors of this paper explored the research related to the rationale to supplement higher education theoretical knowledge with opportunities for students in technology related programs to gain some hands-on experience in the development of a low-cost clustered server environment. The paper also used the widely accepted learning theories of active learning and constructivism to assist in the decision to build the server environment. An explanation of the processes, opportunities, challenges, and outcomes are available in the Server Environment Design and Implementation section. Finally, the paper concludes with implications for students and recommendations for other higher education institutions that are considering enhancing theory with practical hands-on learning opportunities in information technology courses.
\end{abstract}

Keywords: Information technology (IT), Cost benefit, Active learning, Constructivism, Clustering, Repurposing, and Open source

\section{INTRODUCTION}

The information technology curriculum guidelines published by the Association for Computing Machinery (ACM) state that "Information Technology is a laboratory discipline". The success of an information technology program relies on teaching students both soft skills and technical skills that provide opportunities for understanding and modeling organizational processes and data, defining and implementing technical and process solutions, managing products, integrating systems within and across organizations and focusing on the application of information technology in helping individuals, groups, and organizations achieve their goals [38]. Previous research on curriculum development suggested the need for hands-on or active learning projects [21, 33]. Research by Floyd, Harrington, and Santiago [17] suggested that when students in IT programs are exposed to active learning assignments, including hands-on lab exercises, student cognitive engagement or the integration and utilization of students' motivations and strategies in the course of their learning increased. Taylor and White [37] explained that students can acquire technical skills while working on projects as easily, if not better, than with traditional classroom lectures.

There is an increasing acceptance in academia on the value of supplementing theoretical knowledge with hands-on experiential learning $[27,8,4,19,26]$. Some instructors lean toward focusing on conceptual knowledge, while others argue that hands-on activities will engage students' learning experience. In the field of information technology, the ability to provide students with both theory and hands-on experience is particularly important since IT programs aim to provide graduates with the skills and knowledge to be successful in positions in information technology upon graduation and grow into leadership positions or pursue research or graduate studies in the field [1]. Previous studies [22, 23] indicated that there are numerous benefits to hands-on learning, including improved critical thinking and problem solving skills, the ability to apply knowledge in related situations, and increased student interest and motivation. Active learning must have meaningful learning with interesting instructional materials that encourages engaged collaboration. Bonwell and Eison [5] described active learning as a process of actively engaging students in higher-order thinking to construct knowledge. Active learning involves students "doing things" and "thinking about the things they are doing"

The curriculum of an information technology program must be current and competitive to remain relevant and valuable. The addition of hands-on projects to enhance technical skills will only strengthen a student's ability to apply academic skills needed for an increasingly sophisticated workplace and society [9]. Ferreira [15] agreed that 


\section{Issues in Information Systems}

Volume 14, Issue 2, pp.47-53, 2013

technology is becoming embedded in academic life through introducing emerging technologies, course content acquisition, self-assessments, web searches and discussions through a myriad of communication technology. Duffy and Jonassen [12] explained that a course curriculum can remain committed to theory-based instruction as a framework for thinking while simultaneously using a rich array of examples.

The idea that students learn best from experience has its roots in constructivism learning theory. Constructivism learning theory originates from research by Dewey [11], Piaget [31], Vygotsky [40], Ausubel [4], Bruner [7], Ernest [13], and Honebein [18]. Constructivism learning theory underlines construction of new knowledge based on a number of characterizations/elements.

In 1915, John Dewey [11] recognized the importance of experiential learning in the classroom. According to Dewey [11], "The teacher and the book are no longer the only instructors; the hands, the eyes, the ears, in fact the whole body, become sources of information, while teacher and textbook become respectively the starter and the tester. No book or map is a substitute for personal experience; they cannot take the place of the actual journey" [11]. Dewey's [11] emphasis on students' experience is echoed in modern critical thinking about university education.

Vygotsky's [40] theory of social constructivism focused on the interaction of learners with others in cognitive development. The constructivist perspective encourages learning through interaction [36]. According to Brooks and Brooks [6], the use of a lab environment enables instructors to apply concepts recognized as 'constructivist teachers' including:

- assess students' understanding through application and performance of open-structured tasks;

- encourage and accept student autonomy and initiative;

- use a wide variety of materials, including raw data, primary sources, and interactive materials and encourage students to use them;

- inquire about students' understandings of concepts before sharing his/her own understanding of those concepts;

- engage students in experiences that show contradictions to initial understandings and then encourage discussion;

- encourage student inquiry by asking thoughtful, open-ended questions and encourage students to ask questions to each other and seek elaboration of students' initial responses

The opportunity to design, develop, and implement a project will not only provide students with strong technical skills, but also expose them to "real world" issues they are likely to encounter in the work force. During the process, students are able to work one-on-one with faculty. Future students also benefit from such projects as they can be used as a learning tool and the basis for future lab-based work.

\section{A SERVER ENVIRONMENT DESIGN AND IMPLEMENTATION}

The origins of this project to create a clustered server environment from salvage parts began with a brainstorming session intended to investigate potential solutions that would allow students to work with a networked set of servers that could model a complete business solution. To be deemed successful the solution had to satisfy four design goals/criteria: a. The server environment had to be able to mirror the server room functionality of a medium sized business with a web presence. $b$. All technology deployed had to meet the requirements of the Office of Technology Resources at Middle Georgia State College and pose no identifiable security risks to any entities involved in the project. c. The design and implementation had to align with the goals, objectives, and any additional requirements imposed by the Middle Georgia State College School of Information Technology. d. The project had to be completed with minimal cost and demonstrate a significant return on resources invested.

In order to mirror the server functionality of a medium-sized business with a web presence, it was determined that the business' technology would be composed of a clustered server environment that could be used to create an intranet, extranet, and simulated Internet e-commerce site. The intranet and extranet components of the design will be used to provide services to users that are deemed to be employees of the medium-sized business while the e- 


\section{Issues in Information Systems}

Volume 14, Issue 2, pp.47-53, 2013

commerce site will sell services and products to customers via a network connection simulating the Internet [16]. The extranet will be accessed via a connection simulating the Internet as well, but this connection will employ a virtual private network (VPN) connection to mirror common real world practices for setting up a relatively secure connection from employees outside the local area network to access internal network resources (LAN) [10].

The intranet and extranet environment will provide access to applications and services that support communication, productivity, and data storage similar to what would be present in a real world information technology setting supporting routine business functions. The overall functionality of this arrangement will mirror common business functions from small to enterprise level information technology implementations [29]. The clustered servers will house various examples of databases, web sites, and locations for static file storage and dissemination of business documents and policies. The services offered by the clustered server will include support for e-mail, a web server, file transfer protocol, dynamic configuration of client addressing, and name resolution [34]. Mirroring the overall information technology resources of a medium-sized business will allow students to test and implement projects and techniques developed while taking classes in the School of Information Technology while posing substantial threats to interrupting the daily activities of actual business.

The overall inspiration for the design was drawn from a clustering project conducted at Calvin College by Computer Science Professor Joel Adams. Dr. Adams attempted to create a cluster that would increase the price/performance ratio and reduce the overall cost per flop of processing [2]. Adams' Microwulf project began with the creation of four individual computers built from parts that were assembled in a single Plexiglas box. The computers were then networked together to create a communication medium for the connection of the servers to act as a single computer [2]. A networked group of computers that are arranged in this fashion to share the processing load of many jobs through a relatively high speed communication path and appear as a single "super" computer creates a Beowulf cluster [28]. In the spirit of Adams' attempt to reduce costs, we propose creating a similar Beowulf cluster by using a larger quantity of older computers that are destined for salvage or re-purposing.

Our proposed design shown in Figure 1, involves connecting 4-8 salvage computers through an Ethernet switch and managing the computers using a single monitor, keyboard, and mouse connected to the computers via a KVM switch. In an effort to reduce cost, all components of the design will be selected from salvage whenever possible. The minimum requirements for computers selected will be determined based on the goals shown in Table 1 and the availability of salvage computers with homogeneous hardware profiles. In order to reduce the overall software cost associated with the project, open source software solutions will be selected when possible as shown in Table 2. In terms of achieving a suitable return on investment, this goal returns optimal results.

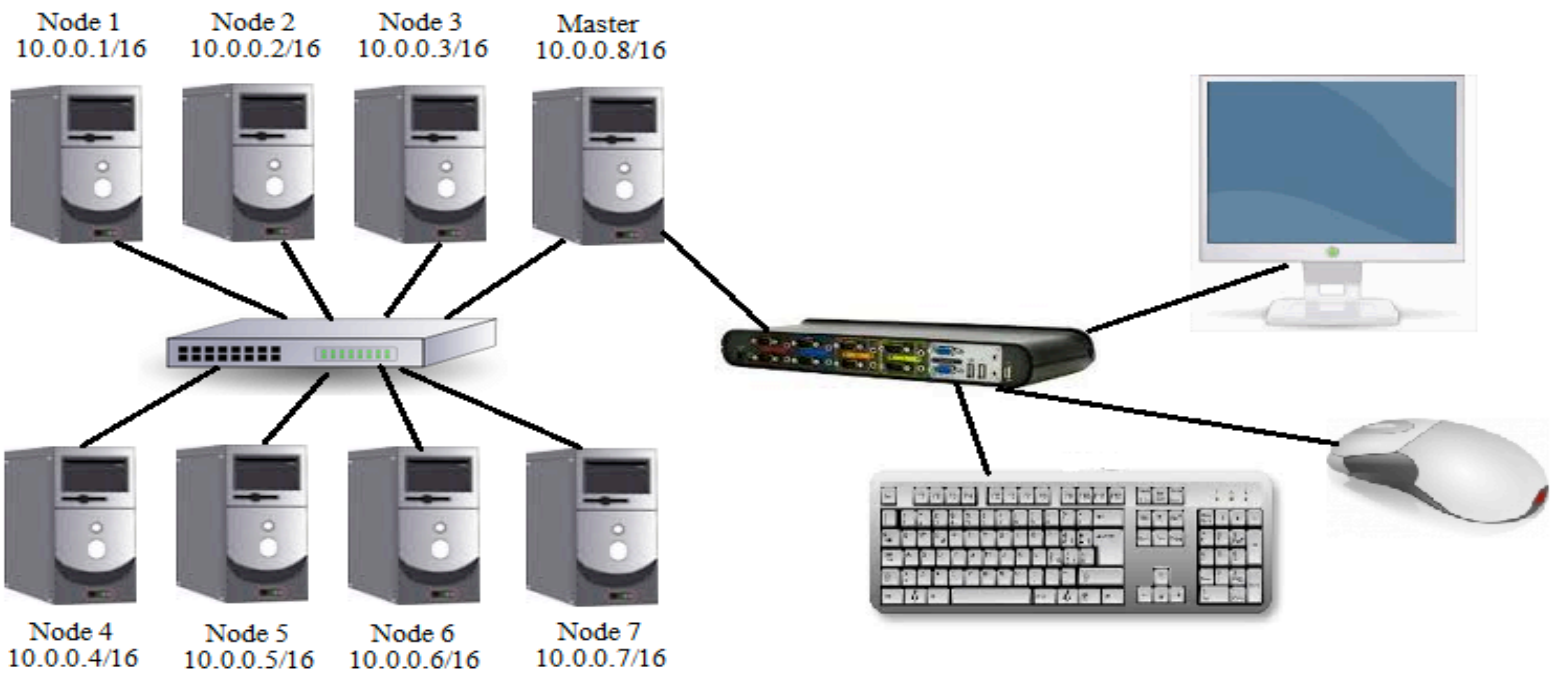

Figure 1. Physical Layout 


\section{Issues in Information Systems}

Volume 14, Issue 2, pp.47-53, 2013

Table 1. Hardware Manifest

\begin{tabular}{|c|c|c|}
\hline Component & Quantity & Design / Specification \\
\hline salvage computers & $4-8$ & $\begin{array}{c}1.0-1.5 \mathrm{GHz} \text { processor, 1 GB } \\
\text { system memory, 20+ GB hard drive }\end{array}$ \\
\hline network interface card & $4-8$ & $10 / 100 \mathrm{Mbs}$, Ethernet \\
\hline LAN switch & 1 & 8 port Ethernet switch \\
\hline Ethernet cabling & $4-8$ & 6 ' Cat 5e straight through cables \\
\hline Monitors & $1-2$ & $17-19$ ' VGA monitor \\
\hline KVM switch & $1-2$ & Supports VGA, PS/2 \\
\hline input devices & $1-2$ of each & $\begin{array}{c}\text { PS/2 optical mouse, PS/2 standard } \\
\text { keyboard }\end{array}$ \\
\hline
\end{tabular}

Table 2. Software Manifest

\begin{tabular}{|c|c|}
\hline Software & Solution \\
\hline Knoppix & Linux operating system - www.knoppix.net \\
\hline OpenMosix & $\begin{array}{c}\text { Application creating/supporting scalable clustering } \\
\text { across PCs - http://sourceforge.net/projects/openmosix }\end{array}$ \\
\hline MySQL & database server - www.mysql.com \\
\hline Apache & Web server - www.apache.org \\
\hline IRedMail & e-mail server - www.iredmail.org \\
\hline
\end{tabular}

The Middle Georgia State College (MGSC) School of Information Technology sets a goal that graduates will become versatilists who "assume productive roles in IT-related positions" and "pursue lifelong learning." The term versatilist refers to the fact that employees in IT-related fields must adapt to changing technology by demonstrating knowledge of theory, applying sound logic, and utilizing skills acquired through practical application. The MGSC School of Information Technology considers the aspects of core knowledge to be comprised of "programming, application development, Web design, systems analysis and design, human computer interaction, interactive digital media, database principles, Web programming, project management, IT organizational integration, legal and ethical issues in information technology, and foundations of information assurance." To meet the criteria of supporting the goals and objectives of the MGSC School of Information Technology it was deemed necessary that the proposed solution would need to support a number of the core objectives. As seen in Table 3, the proposed solution meets the majority of the objectives along with supporting faculty and student research.

The composition and structure of this implementation poses no threat to the daily activities of the host school's web presence or support of faculty and students since the cluster exists as a private network housed on the school's campus. Students and faculty that access and utilize the Beowulf cluster will use specific clients that are isolated from the school's network and the Internet to access and test resources in the cluster's private network. Additionally, the enforcement of security policies on the clustered network becomes an academic endeavor in itself that creates an active learning project for the School of Information Technology's students that are exploring a security concentration. 


\section{Issues in Information Systems}

Volume 14, Issue 2, pp.47-53, 2013

Table 3. Disciplines and the active learning opportunities supported

\begin{tabular}{|c|c|}
\hline Disciplines Supported & Active Learning Opportunities \\
\hline Networking & $\begin{array}{l}\text { 1. Use of open source software and operating } \\
\text { systems } \\
\text { 2. Networking servers } \\
\text { 3. Creating / managing a cluster environment } \\
\text { 4. Supporting /managing multiple user } \\
\text { connections } \\
\text { 5. Support name resolution for intranet }\end{array}$ \\
\hline Security & $\begin{array}{ll}\text { 1. } & \text { Applying best practices for security } \\
\text { 2. } & \text { Securing databases } \\
\text { 3. } & \text { Securing a web server }\end{array}$ \\
\hline Web Design & $\begin{array}{l}\text { 1. Support student development of web pages in a } \\
\text { real world environment } \\
\text { 2. Facilitate group interaction in web development } \\
\text { 3. Host student / class web pages } \\
\text { 4. Support client-side scripting languages }\end{array}$ \\
\hline Database & $\begin{array}{l}\text { 1. Support student developed databases } \\
\text { 2. Allow networked connections to databases } \\
\text { 3. Facilitate connecting web pages and } \\
\text { applications to a database }\end{array}$ \\
\hline Software Development & $\begin{array}{l}\text { 1. Support server-side programming } \\
\text { 2. Support student development of web } \\
\text { applications } \\
\text { 3. Support development of three-tiered } \\
\text { applications }\end{array}$ \\
\hline Capstone / Project / Research & $\begin{array}{l}\text { 1. Allow students to model real world business } \\
\text { environments } \\
\text { 2. Facilitate group interaction that spans multiple } \\
\text { disciplines } \\
\text { 3. Support academic research }\end{array}$ \\
\hline
\end{tabular}

\section{BENEFITS AND IMPLICATIONS}

Favero and Hinson [14] asserted that successful information technology implementations support users but serve an additional function as a marketing tool for attracting potential students. Aside from the benefits of potential active learning opportunities, technology projects also encourage student adoption and interest by appealing to a sense of playfulness that in turn fosters learning [39]. Student interest is further increased when hands-on projects deliver immediate feedback [20]. In the case of this proposed project, immediate feedback is supported in almost every discipline offered within the School of Information Technology. Additionally, this project avoids many pitfalls that lead instructors to avoid adopting technology solutions. For example investment of capital and resources is not an issue when an entire project is accomplished using salvage materials. Polites and Karahanna [32] stated that instructors will be highly likely to adopt projects solution that pose little threat to losing sunk cost or increasing risk with regard to expended resources. The salvage Beowulf cluster solves another drawback to technology adoption in that there is no concern for lacking technology infrastructure since the project establishes a suitable infrastructure in its design [30]. 


\section{Issues in Information Systems}

Volume 14, Issue 2, pp.47-53, 2013

The proposed solution supports collaboration between researchers, colleagues, and students. The facilitation of collaboration allows influential users to become champions and trainers of new technologies. This role as a power user or champion allows anyone with expertise in an area to become a mentor for others in the communication channel [35]. As relationships and utilization grows centered around the project, the parameters and specifications can be expanded to support proprietary software solutions and new fields of interest. The cost-benefit paradigm is maximized by showing benefits across all fields of interest while showing only labor as an associated cost [25]. The resulting labor is offset by the labor expended being transformed in active learning opportunities for students involved in the project [24].

\section{CONCLUSIONS}

The relative value of any technology-enhanced learning tool is challenging to gauge in the present regardless of whether the leadership of an institution evaluates cost in terms of resources used or effort expended [25]. In the case of the repurposing of salvage technology that is implemented with labor resulting from student active learning activities, it is difficult to view this implementation of technology-enhanced learning as anything but a value for all parties that are involved. The implementation proposed in this paper satisfies all four criteria expressed for creating a successful solution: the information technology environment of a medium-sized business is created with suitable scalability to accommodate the future growth of the school, isolation from the school network and sound security practices comply with requirements imposed by the Office of Technology Resources, students become versatilists that possess theoretical knowledge supported by experience gained from practical application, and a sound return on investment is observed by all stakeholders.

\section{REFERENCES}

1. ACM. (2008). Information technology 2008: Curriculum guidelines for undergraduate degree programs in information technology. http://www.acm.org/education/curricula/IT2008\%20Curriculum.pdf

2. Adams, J. (2007). Microwulf: A personal, portable Beowulf cluster. Retrieved from http://www.calvin.edu/ adams/research/microwulf/.

3. Aravena M, \& Andres,R. (2009). Use of a remote network lab as an aid to support teaching computer. CLEI Electronic Journal,12(1), 8

4. Ausubel, D. Educational psychology: A cognitive view. New York: Holt, Rinehart \& Winston, 1968.

5. Bonwell, C., \& Eison, J. (1991). Active learning: Creating excitement in the classroom. Washington, DC: ASHE - ERIC Higher Education Report No. 1.

6. Brooks, J. G. and Brooks, M. G. (1993). In search of understanding: the case for constructivist classrooms, Alexandria, VA: American Society for Curriculum Development.

7. Bruner, J. (1990). Acts of Meaning. Cambridge, MA: Harvard University Press.

8. Cigas, J. (2002). A computer networking laboratory for administration and networking. Frontiers in Education,1(T3D), 12-11.

9. Daggett, W. (2010). Preparing students for their technological future . International Center for Leadership in Education, Retrieved from http://www.leadered.com/pdf/Preparing Students for Tech Future white paper.pdf

10. Dean, T. (2013). Network+: Guide to Networks. Boston: Course Technology.

11. Dewey, J., \& Dewey E. (2007). Schools of Tomorrow. Whitefish, MT: Kessinger Publishing. (Original work published 1915).

12. Duffy, T. M., \& Jonassen, D. H. (1992). Constructivism and the technology of instruction: a conversation. (Thomas M Duffy \& David H Jonassen, Eds.). Computers in Human Behavior (Vol. In Press,, p. 221). Lawrence Erlbaum Associates. Retrieved from http://books.google.com/books?id=7Uv8NHvKK44C

13. Ernest, P. (1995). The one and the many. In L. Steffe \& J. Gale (Eds.). Constructivism in education(pp.459486). New Jersey: Lawrence Erlbaum Associates, Inc.

14. Favero, M., \& Hinson, J. (2007). Evaluating instructor technology integration in community and technical colleges: A performance evaluation matrix. Community College Journal of Research and Practice, 31, 389408. doi: 10.1080/10668920701282775

15. Ferreira, M. J. M. (2010). Intelligent classrooms and smart software: Teaching and learning in today's university. Education and Information Technologies, 1-23. Springer Netherlands. Retrieved from 


\section{Issues in Information Systems}

Volume 14, Issue 2, pp.47-53, 2013

http://www.springerlink.com/index/10.1007/s10639-010-9134-8

16. Fitzgerald, J., \& Dennis, A. (2007). Business Data Communications and Networking. Hoboken, NJ: John Wiley and Sons, Inc.

17. Floyd, K. S., Harrington, S. J., \& Santiago, J. (2009). Improving I.S. student engagement and perceived course value. Proceedings of the 2009 Southern Association for Information Systems Conference, 24-29.

18. Honebein, P. (1996). Seven goals for the design of Constructivist learning environments. In B. Wilson, Constructivist learning environments, pp. 17-24. New Jersey: Educational Technology Publications.

19. Imboden, T., \& Strothmann, D. (2010). Design and implementation of a low-cost networking and voip lab for undergraduate networking curriculum instruction. Issues in Information Systems, 11(2), 1-6.

20. Kanthawongs, P. (2011). Technology acceptance model and motivational model contributing to student satisfaction in erp-simulated web-enhanced course. Review of Business Research, 11(1), 117-121. http://www.iabe.org/domains/iabe/journal.aspx? journalid $=5$

21. Keys, A. (2002). Using group projects in MIS: strategies for instruction and management. Journal of Computer Information Systems, 42-50.

22. Kinsley, C.W. (1993). Community service learning as a pedagogy,Equity and Excellence in Education, 26(2), 53-63.

23. Kinsley, C.W. (1994). What is community service learning? Vital Speeches of the Day. 61(2), 40-43.

24. Kolb, A. Y. \& Kolb, D. A. (2005). Learning styles and learning spaces: Enhancing experiential learning in higher education. Academy of Management Learning \& Education, 4(2), 193-212.

25. Laurillard, D. (2007). Modeling benefits-oriented costs for technology enhanced learning. Higher Education, 54, 21-39.

26. McGann, S.T., Cahill, M.A. (2005). Pulling it all together: An is capstone course for the $21^{\text {st }}$ century emphasizing experiential \& conceptual aspects, soft skills, and career readiness. Issues in Information Systems, 6(1), 391-397.

27. Mengel, S. A., \& Bowling, C. D. (1995). Supporting networking courses with a hands-on laboratory. Frontiers in Education Conference, 1995. Proceedings., 1995(Vol. 2, p. 4c2.20-4c2.23 vol.2). Presented at the Frontiers in Education Conference, 1995. Proceedings., 1995. doi:10.1109/FIE.1995.483214

28. Michigan Tech (2000). Beowulf Cluster Computing. Retrieved from http://www.cs.mtu.edu/beowulf/.

29. Panko, R. (2007). Business Data Networks and Telecommunications. Upper Saddle River, NJ: Pearson Prentice Hall.

30. Park, S. (2009). An analysis of the Technology Acceptance model in understanding university students' behavioral intention to use e-Learning. Education Technology \& Society, 13(3), 150-162.

31. Piaget, J. (1972). The psychology of the child. New York: Basic Books.

32. Polites, G. L., \& Karahanna, E. (2012). Shackled to the status quo: the inhibiting effects of incumbent system habit, switching costs, and inertia on new system acceptance. MIS Quarterly, 36(1), 21-A13.

33. Scott, E. (2004). Systems Development Group Project: A Real World Experience. ISECON 2004, 21,1-8.

34. Silva, S. (2007). Web Server Administration. Boston: course Technology.

35. Sykes, T., Venkatesh, V., \& Gosain, S. (2009). Model of acceptance with peer support: a social network perspective to understand employees' system use. MIS Quarterly, 33(2), 371-393.

36. Tam, M. (2000). Constructivism, instructional design, and technology: Implications for transforming distance learning. Educational Technology \& Society, 3(2), Retrieved from http://www.ifets.info/journals/3_2/tam.html

37. Taylor, M., White, B.J. (2011). Real world information systems projects in the classroom: Factors to consider. Issues in Information Systems, 12(2), 135-141.

38. Topi, H., Valacich, J.S., Wright, R.T., Kaiser, K.M., Nunamaker, J.F., Sipior, J.C., de Vreede, G.J. (2010). IS 2010: Curriculum guidelines for undergraduate degree programs in information systems. Retrieved from http://www.acm.org/education/curricula/IS\%202010\%20ACM\%20final.pdf.

39. Venkatesh, V., \& Bala, H. (2008). Technology Acceptance Model 3 and a research agenda on interventions. Decision Sciences, 39(2), 273-315. doi: 10.1111/j.1540-5915.2008.00192.x

40. Vygotsky, L.S. (1978). Mind and society: The development of higher mental processes. Cambridge, MA: Harvard University Press. 